\title{
PENGARUH SUBJECTIVE NORM DAN PERCEIVED BEHAVIORAL CONTROL TERHADAP INTENTION TO COMMIT DIGITAL PIRACY
}

\author{
Tommy Setiawan Ruslim, Mukti Rahardjo dan Hannes Widjaya \\ Fakultas Ekonomi Universitas Tarumanagara \\ Email: rahardjo_mukti@yahoo.com
}

\begin{abstract}
In the era of computerization today, almost every company big and small use computers in running its business activities. Even not only within the scope of the company, both of the students, other businessmen are also many who use computers to help business activities. The high level of demand for the needs of the software to create a number of parties to create pirated software with a much cheaper price, so it is allegedly can make software makers experience losses of course. By doing a similar research as conducted by Yoon (2011), the authors conducted research on the intention to perform digital piracy in S1 Management Faculty of Economics Tarumanagara University. By using questionnaires, data is processed with PASW 18.00 software, there is also result of this research is subjective norm as independent variable (X1) and perceived behavioral control (X2) have significant influence to intention to commit digital piracy (Y).
\end{abstract}

Keywords: subjective norm, perceived behavioral control, intention to commit digital piracy.

\begin{abstract}
Abstrak: Di era komputerisasi saat ini, hampir setiap perusahaan baik besar maupun kecil menggunakan komputer dalam menjalankan kegiatan bisnisnya. Bahkan tidak hanya dalam lingkup perusahaan, baik dari para kalangan pelajar, pebisnis lainnya pun banyak yang memanfaatkan komputer guna membantu kegiatan bisnisnya. Tingginya tingkat permintaan akan kebutuhan dari software membuat sejumlah pihak untuk membuat software bajakan dengan harga yang jauh lebih murah, sehingga hal tersebut disinyalir dapat membuat perusahaan pembuat software mengalami kerugian tentunya. Dengan melakukan penelitian serupa seperti yang dilakukan oleh Yoon (2011), penulis melakukan penelitian mengenai niat untuk melakukan pembajakan digital di S1 Manajemen Fakultas Ekonomi Universitas Tarumanagara. Dengan menggunakan kuesioner, data diolah dengan software PASW 18.00, ada pun hasil penelitian ini adalah subjective norm sebagai variabel independen (X1) dan perceived behavioral control (X2) memiliki pengaruh yang signifikan terhadap intention to commit digital piracy $(\mathrm{Y})$.
\end{abstract}

Kata kunci: subjective norm, perceived behavioral control, intention to commit digital piracy.

\section{PENDAHULUAN}

Di era komputerisasi saat ini, hampir setiap perusahaan baik besar maupun kecil menggunakan komputer dalam menjalankan kegiatan bisnisnya. Bahkan tidak hanya dalam lingkup perusahaan, baik dari para kalangan pelajar, pebisnis lainnya pun banyak yang memanfaatkan komputer guna membantu kegiatan bisnisnya. Penggunaan software pada komputer sudah menjadi hal yang wajib, mengingat setiap komputer membutuhkan program-program sesuai kebutuhan konsumennya, misalnya: antivirus, program microsoft, mediaplayer, dan sebagainya. 
Tingginya tingkat permintaan akan kebutuhan dari software membuat sejumlah pihak untuk membuat software bajakan dengan harga yang jauh lebih murah, sehingga hal tersebut disinyalir dapat membuat perusahaan pembuat software mengalami kerugian tentunya. Menurut Yoon (2011), upaya terus-menerus untuk mengurangi pembajakan digital, peneliti dari berbagai bidang seperti etika bisnis, pemasaran, dan sistem informasi, selama dekade terakhir, mengusulkan berbagai model untuk memahami sifat dari perilaku pembajakan digital dan faktor-faktor yang mempengaruhinya niat berperilaku individu untuk melakukan pembajakan digital.

Yoon (2011), berbagai penelitian terhadulu banyak yang membahas tentang pembajakan digital dengan menggunakan teori perilaku seperti teori TRA (theory of reasoned action) atau TPB (theory of planned behavior) sebagai teori dasar untuk menjelaskan tingkah laku untuk melakukan pembajakan digital, beberapa penelitian lain telah mempertimbangkan bahwa pembajakan digital merupakan perilaku yang tidak etis, mereka membuat model penelitiannya dengan menggunakan teori etika.

Berdasarkan narasi di atas, peneliti hendak membuat sebuah model terpadu untuk sepenuhnya memahami tingkah laku dari niat individu seseorang untuk melakukan pembajakan digital, yang menggabungkan teori perilaku dan teori etika. Dengan melakukan penelitian serupa seperti yang dilakukan oleh Yoon (2011), penulis melakukan penelitian mengenai niat untuk melakukan pembajakan digital di S1 Manajemen Fakultas Ekonomi Universitas Tarumanagara.

Permasalahan dalam penelitian ini adalah: Apakah terdapat pengaruh yang signifikan subjective norm terhadap intention to commit digital piracy?; Apakah terdapat pengaruh yang signifikan perceived behavioral control terhadap intention to commit digital piracy?: Apakah terdapat pengaruh yang signifikan subjective norm dan perceived behavioral control terhadap intention to commit digital piracy?

Dalam penelitian ini, pembatasan dalam ruang lingkupnya adalah: variabel independennya adalah subjective norm dan perceived behavioral control. Dengan intention to commit digital piracy sebagai variabel dependen. Periode pembagian kuesioner adalah bulan Juli 2017 terhadap mahasiswa S1 Manajemen Universitas Tarumanagara yang pernah melakukan pembajakan digital baik mendownload dari internet atau membeli atau menggunakan software bajakan.

\section{KAJIAN TEORI}

Teori TPB dalam pembajakan digital. Dalam Yoon (2011), teori TPB adalah teori ekstensi / perpanjangan dari teori TPA oleh Fishbein dan Ajzen's (1975) yang mengusulkan memprediksi dan memahami tentang perilaku tertentu dalam konteks yang ditentukan (Ajsen, 1991). Menurut teori TPB, perilaku seseorang sebenarnya dipengaruhi langsung oleh niat tingkah lakunya, di mana pada gilirannya akan bersama-sama ditentukan oleh sikapnya, norma subjektif, dan control perilaku yang dirasakan terhadap kinerja perilaku itu. Sikap terhadap tingkah laku itu didefinisikan sebagai penilaian orang yang baik atau tidak baik terhadap perilaku yang bersangkutan. Sebuah sikap baik atau tidak baik secara langsung dipengaruhi dengan kekutan perilaku dan kepercayaan tentang kemungkinan hasilnya. Norma subyektif lebih merujuk untuk tekanan sosial yang dirasakan untuk melakukan atau tidak lakukan pada tingkah laku yang bersangkutan.

Menurut Lin, et al. 1999 dalam Yoon (2011), teori TPB adalah model dari niat yang diteliti dengan baik dan telah terbukti berhasil dalam memprediksi dan menjelaskan 
perilaku di berbagai domain. Dengan demikian, sejumlah penelitian terdahulu pun telah dilakukan dalam pembajakan software yang menggunakan teori TPB sebagai teori dasar untuk menjelaskan maksud perilaku individu tersebut (Kwong dan Lee, 2002) dalam Yoon (2011). Hasil penelitannya menunjukkan bahwa pencegahan legislasi, sikap, norma subjektif dan kontrol perilaku yang dirasakan memiliki dampak yang signifikan terhadap niat perilaku.

Teori etika dalam pembajakan digital. Banyak penelitian / studi tentang pembajakan digital, beberapa peneliti menggambarkannya sebagai perilaku yang tidak etis. Yoon (2011), model yang sering digunakan dalam studi pembajakan digital adalah model keputusan etis Hunts dan Vitell (1986). Model ini adalah teori umum etika pemasaran, yang berfokus pada proses penalaran yang digunakan oleh individu tersebut. Cronan dan Al-Rafee (2008) dalam Yoon (2011) mengungkapkan bahwa kewajiban moral, serta variabel TPB, mempengaruhi niat pembajakan digital. Teori teleologis yang didasarkan pada tujuan hasil, tujuan, atau tujuan suatu tindakan tertentu. Walaupun teori teleologis terbagi dalam egoisme (sebuah tindakan, atau seharusnya, dilakukan untuk tindakan seseorang diri) dan utilitarianisme (sebuah tindakan ditentukan oleh kontribusi terhadap kebahagiaan atau kesenangan yang terbesar jumlah orang), gagasan teleologis dalam pembajakan digital literatur diwakili dalam hal konsekuensi yang dirasakan, terutama manfaat yang dirasakan.

Berdasarkan penelitian yang dilakukan oleh : Yoon (2011) yang berjudul Theory of Planned Behavior and Ethics Theory in Digital Piracy: An Integrated Model, diperoleh hasil sebagai berikut : "Since digital piracy has posed a significant threat to the development of the software industry and the growth of the digital media industry, it has, for the last decade, held considerable interest for researchers and practitioners. This article will propose an integrated model that combines the theory of planned behavior $(T P B)$ and ethics theory, the two theories that are most often used in digital piracy studies. Data were obtained from university students in China, and the model was examined using the structural equation model (SEM). The results show that moral obligation and justice, derived from ethics theories and TPB variables, such as attitude, subjective norms, and perceived behavioral control, influence the behavioral intentions of individuals to commit digital piracy. The attitude of individuals toward digital piracy is also found to be influenced by perceived benefits, perceived risk, and habit."

\section{METODE}

Menurut Supranto (2003:68), metode pengumpulan data dengan jalan mencatat seluruh elemen yang dijadikan obyek penelitian disebut dengan sensus, sedangkan kumpulan dari seluruh elemen obyek penelitian tersebut dinamakan populasi. Populasi dalam penelitian ini adalah seluruh mahasiswa S1 Manajemen Fakultas Ekonomi Universitas Tarumanagara yang pernah melakukan pembajakan digital, baik dari mendownload atau pun membeli atau menggunakan software-software bajakan. Instrumen yang digunakan dalam penelitian ini adalah kuesioner. Teknik pemilihan sampel yang digunakan adalah purposive sampling, yaitu teknik penentuan sampling dengan pertimbangan tertentu. (Sugiyono, 2006). Menurut Gay dan Diehl dalam Kuncoro (2003), bahwa untuk studi korelasional dibutuhkan minimal 30 sampel untuk menguji ada atau tidaknya hubungan. Maka, dengan besarnya sampel yang diambil dalam penelitian ini adalah sebesar 60 responden, namun dari 60 
kuesioner yang disebar hanya sebesar 53 kuesioner yang terisi secara lengkap dan bisa digunakan dalam penelitian ini.

Tabel 1. Indikator Variabel Subjective Norm (X1)

\begin{tabular}{cll}
\hline Variabel & \multicolumn{1}{c}{ Indikator Pengukuran } & \multicolumn{1}{c}{ Skala } \\
\hline & $\begin{array}{l}\text { Jika saya melakukan pembajakan digital, } \\
\text { orang-orang yang penting dalam hidup saya } \\
\text { akan menolaknya }\end{array}$ & \\
& $\begin{array}{l}\text { Kebanyakan orang yang penting dalam hidup } \\
\text { Saya akan memandang rendah saya jika saya }\end{array}$ & Sangat Tidak Setuju (STS) $=5$ \\
Tidak Setuju (TS) $=4$ & Netral (N) $=3$ \\
Norm & melakukan pembajakan digital & Setuju (S) $=2$ \\
& $\begin{array}{l}\text { Tidak ada orang yang penting dalam hidup } \\
\text { saya, yang berpikir bahwa boleh saja untuk }\end{array}$ & Sangat Setuju (SS) $=1$ \\
& $\begin{array}{l}\text { melakukan pembajakan digital } \\
\text { Rekan-rekan saya menganggap pembajakan } \\
\text { digital itu salah }\end{array}$ & \\
\hline
\end{tabular}

Sumber: Yoon (2011).

Tabel 2. Indikator Variabel Perceived Behavioral Control (X2)

\begin{tabular}{cll}
\hline Variabel & \multicolumn{1}{c}{ Indikator Pengukuran } & \multicolumn{1}{c}{ Skala } \\
\hline & $\begin{array}{l}\text { Bagi saya, adalah mudah untuk mendapatkan } \\
\text { produk digital bajakan }\end{array}$ & Sangat Tidak Setuju (STS) =1 \\
Perceived & Saya memiliki kemampuan untuk & Tidak Setuju (TS) $=2$ \\
Behavioral & memanfaatkan produk digital bajakan & Netral $(\mathrm{N})=3$ \\
Control & $\begin{array}{l}\text { Saya bisa menemukan produk digital bajakan } \\
\text { jika saya mau }\end{array}$ & Setuju (S) $=4$ \\
& Sangat Setuju (SS) $=5$ \\
& $\begin{array}{l}\text { Produk digital bajakan sepenuhnya berada } \\
\text { dalam kendali saya }\end{array}$ & \\
\hline Sumber: Yoon $(2011)$
\end{tabular}

Tabel 3. Indikator Intention To Commit Digital Piracy (Y)

\begin{tabular}{cll}
\hline Variabel & \multicolumn{1}{c}{ Indikator Pengukuran } & \multicolumn{1}{c}{ Skala } \\
\hline & Saya berniat membajak produk digital dalam & Sangat Tidak Setuju (STS) = \\
Intention To & waktu dekat & 1 \\
Commit & Jika saya punya kesempatan, saya akan & Tidak Setuju (TS) =2 \\
Digital & membajak produk digital & Netral (N) =3 \\
Piracy & Saya tidak pernah melakukan pembajakan & Setuju (S) =4 \\
& Sangat Setuju (SS) =5 \\
& digital* & \\
\hline
\end{tabular}

Keterangan : *skala dibalik

Sumber : Yoon (2011).

Sesuai dengan penelitian terdahulu di atas, maka kerangka dalam penelitian ini pun secara praktis disajikan dalam gambar sebagai berikut: 


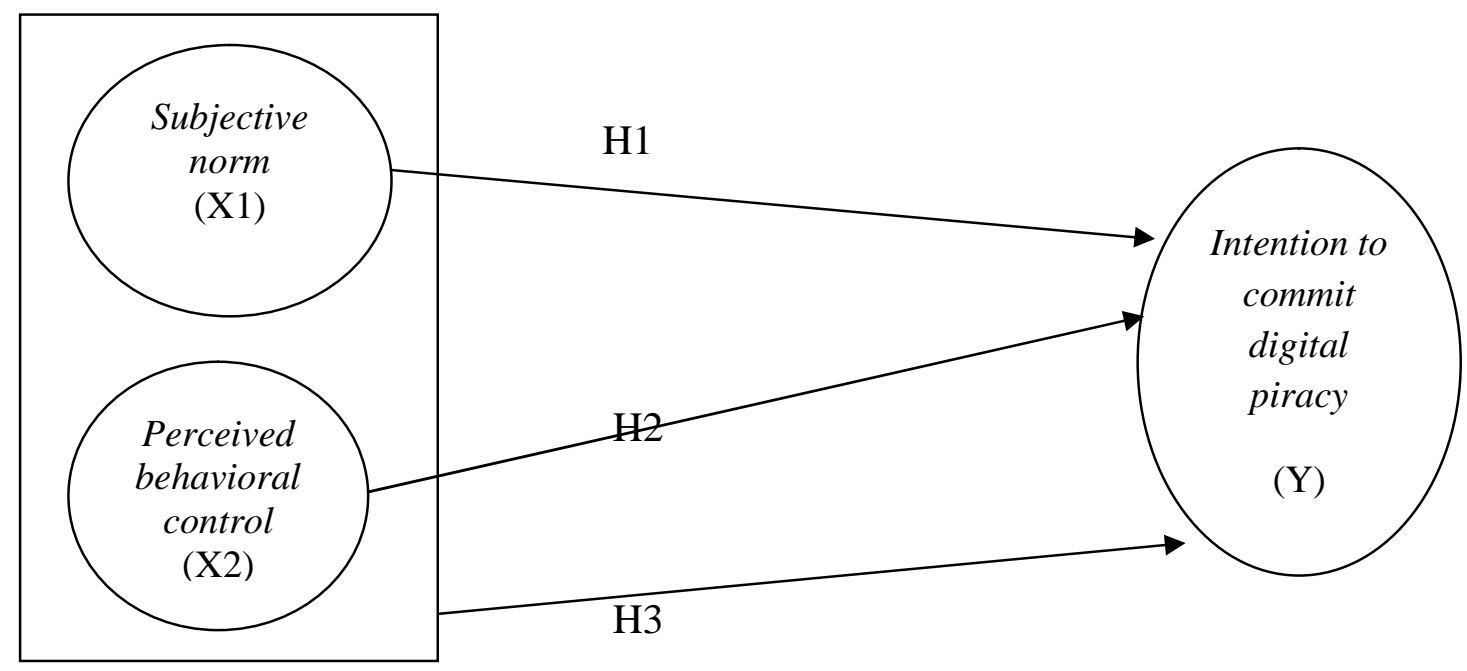

Dalam penelitian ini, terdapat 3 (tiga) hipotesis yang akan diuji, yaitu:

H1: Terdapat pengaruh yang signifikan subjective norm terhadap intention to commit digital piracy.

H2: Terdapat pengaruh yang signifikan perceived behavioral control terhadap terhadap intention to commit digital piracy.

H3 : Terdapat pengaruh yang signifikan subjective norm dan perceived behavioral control terhadap intention to commit digital piracy.

Uji Validitas Dan Uji Reliabilitas Kuesioner. Menurut Aritonang (2007:123), suatu instrumen dinyatakan valid bila instrumen itu dapat mengukur apa yang dimaksudkan untuk diukur oleh instrumen itu. Validitas menunjukkan sejauh mana suatu alat pengukur itu mengukur apa yang ingin diukur. Menurut Formell \& Lacker (dalam Aritonang 2007:133), pengujian validitas konvergen yang dikoreksi dinyatakan valid apabila $\geq 0,2$.

Sedangkan menurut Ghozali (2006), pengujian reliabilitas instrumen diuji dengan menggunakan Cronbach's Alpha. Realibilitas suatu konstruk variabel dikatakan baik jika memiliki nilai Cronbach's Alpha > dari 0,6 dan apabila nilai Cronbach's Alpha < dari 0,6 maka hal ini mengindikasikan ada beberapa responden yang menjawab tidak konsisten dan harus kita lihat satu persatu jawaban responden yang tidak konsisten harus dibuang dari analisis dan alpha akan meningkat.

\section{HASIL DAN PEMBAHASAN}

Analisis Deskriptif. Berdasarkan data yang dikumpulkan dari hasil penyebaran kuesioner, data tersebut kemudian diolah dan dianalisis. Sehingga diperoleh informasi mengenai respondennya adalah sebagai berikut:

1. Jenis kelamin responden. Sebanyak 28 responden adalah pria $(52,83 \%)$ dan 25 responden adalah wanita $(47,17 \%)$.

2. Semester. Sebanyak 8 responden adalah semester 1 sampai $3(15,09 \%)$; sebanyak 23 responden adalah semester 4 sampai 6 (43,40\%); sebanyak 22 responden adalah semester $>7(41,51 \%)$. 
Pengujian Validitas dan Reliabilitas. Pengujian validitas dan reliabilitas yang dilakukan pada setiap indikator dari masing-masing variabel menunjukkan hasil sebagai berikut:

Tabel 4. Pengujian Validitas Butir Pertanyaan Subjective Norm (X1)

\begin{tabular}{ccc}
\hline Butir Pertanyaan & $\begin{array}{c}\text { Corrected Item - } \\
\text { Total Correlation }\end{array}$ & Kesimpulan \\
\hline 1 & 0,763 & Valid \\
2 & 0,611 & Valid \\
3 & 0,652 & Valid \\
4 & 0,679 & Valid \\
\hline
\end{tabular}

Tabel 5. Pengujian Validitas Butir Pertanyaan Perceived Behavioral Control (X2)

\begin{tabular}{ccc}
\hline Butir Pertanyaan & $\begin{array}{c}\text { Corrected Item - } \\
\text { Total Correlation }\end{array}$ & Kesimpulan \\
\hline 1 & 0,751 & Valid \\
2 & 0,560 & Valid \\
3 & 0,639 & Valid \\
4 & 0,749 & Valid \\
\hline
\end{tabular}

Tabel 6. Pengujian Validitas Intention To Commit Digital Piracy (Y)

\begin{tabular}{ccc}
\hline Butir Pertanyaan & $\begin{array}{c}\text { Corrected Item - } \\
\text { Total Correlation }\end{array}$ & Kesimpulan \\
\hline 1 & 0,516 & Valid \\
2 & 0,413 & Valid \\
3 & 0,394 & Valid \\
\hline
\end{tabular}

Tabel 7. Pengujian Reliabilitas

\begin{tabular}{ccc}
\hline Variabel & Alpha Cronbach & Kesimpulan \\
\hline Subjective Norm & 0,752 & Reliabel \\
Perceived Behavioral Control & 0,753 & Reliabel \\
Intention To Commit Digital Piracy & 0,625 & Reliabel \\
\hline
\end{tabular}

\section{Pengujian Asumsi}

Tabel 8. Multikolinearitas

Collinearity Statistics

\begin{tabular}{lll}
\hline Tolerance & & \\
\hline & & \\
& & \\
& .171 & 5.858 \\
.171 & 5.858 \\
\hline
\end{tabular}

Dari hasil pengujian multikolinearitas dengan menggunakan PASW 18.00, nilai Variance Inflation Factor (VIF) bernilai di bawah 10, sehingga dapat disimpulkan tidak terjadi multikolinearitas. 


\section{Normalitas}

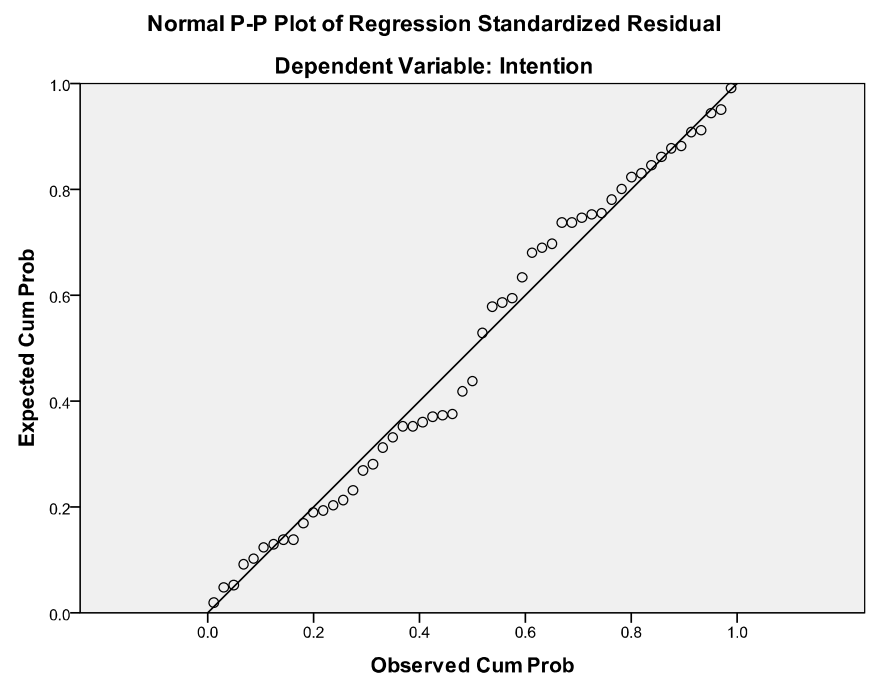

Gambar 1. P-P Plot

Dari gambar Normal P-P Plot, titik-titik data yang menyebar di sekitar garis diagonal, dan penyebaran titik-titik data searah mengikuti garis diagonal. Sehingga dapat disimpulkan data sudah terdistribusi secara normal.

\section{Heteroskedastisitas}

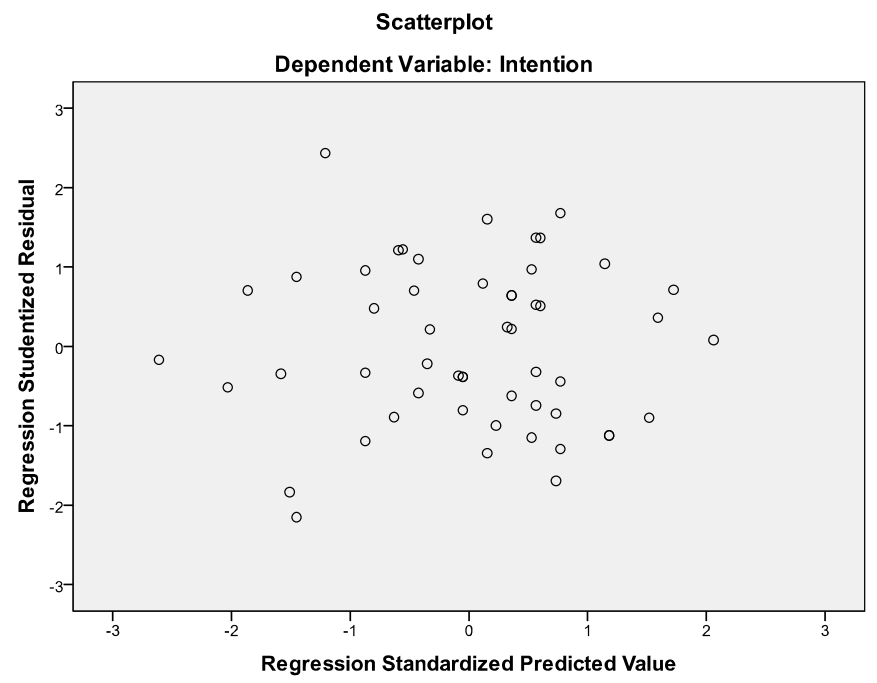

Gambar 2. Scatterplot,

Dari gambar Scatterplot, dapat dilihat bahwa tidak ada pola yang jelas, serta titik-titik menyebar di atas dan di bawah angka 0 pada sumbu Y, maka disimpulkan tidak terjadi heteroskedastisitas.

Uji Hipotesis. Pertama. Uji pengaruh secara parsial dengan uji t. Pengujian pengaruh variabel independen terhadap variabel dependen secara parsial dilakukan dengan melihat hasil output PASW 18.00 sebagai berikut: 


\begin{tabular}{|c|c|c|c|c|c|c|c|}
\hline \multicolumn{8}{|c|}{$\begin{array}{c}\text { Tabel 9. Coefficients } \\
\text { Coefficients }^{\mathrm{a}}\end{array}$} \\
\hline \multirow[t]{2}{*}{ Model } & \multicolumn{2}{|c|}{$\begin{array}{c}\text { Unstandardized } \\
\text { Coefficients }\end{array}$} & \multirow{2}{*}{$\begin{array}{c}\begin{array}{c}\text { Standardized } \\
\text { Coefficients }\end{array} \\
\text { Beta } \\
\end{array}$} & \multirow[b]{2}{*}{$\mathrm{t}$} & \multirow[b]{2}{*}{ Sig. } & \multicolumn{2}{|c|}{$\begin{array}{c}\text { Collinearity } \\
\text { Statistics }\end{array}$} \\
\hline & $\mathrm{B}$ & Std. Error & & & & Tolerance & VIF \\
\hline 1 (Constant) & 6.508 & 1.277 & & 5.096 & .000 & & \\
\hline $\begin{array}{l}\text { Subjective } \\
\text { Norm }\end{array}$ & .800 & .226 & 1.043 & 3.533 & .001 & .171 & 5.858 \\
\hline $\begin{array}{l}\text { Perceived } \\
\text { Behavioral } \\
\text { Control }\end{array}$ & -.517 & .223 & -.684 & -2.318 & .025 & .171 & 5.858 \\
\hline
\end{tabular}

Tabel di atas menunjukkan besarnya nilai signifikansi untuk setiap variabel independen lebih kecil daripada $\alpha(0,05)$. Dengan demikian, hipotesis yang telah dirumuskan pada bab sebelumnya pembuktiannya adalah sebagai berikut: (1) H1 diterima, terdapat pengaruh yang signifikan subjective norm terhadap intention to commit digital piracy.; (2) $\mathrm{H} 2$ diterima, terdapat pengaruh yang signifikan perceived behavioral control terhadap intention to commit digital piracy.

\section{Uji pengaruh secara bersama-sama dengan uji ANOVA}

Tabel 10. ANOVA ${ }^{b}$

\begin{tabular}{llrrrrr}
\hline Model & & Sum of Squares & df & Mean Square & F & Sig. \\
1 & Regression & 99.167 & 2 & 49.583 & 8.614 & $.001^{\text {a }}$ \\
& Residual & 287.814 & 50 & 5.756 & & \\
& Total & 386.981 & 52 & & & \\
\hline
\end{tabular}

a. Predictors: (Constant), Perceived Behavioral Control, Subjective Norm

b. Dependent Variable: Intention

Pada Tabel 10 ANOVA $^{\mathrm{b}}$ diketahui bahwa nilai sig. adalah sebesar 0,001 lebih kecil daripada $\alpha(0,05)$. Dengan demikian, hipotesis yang telah dirumuskan pada bab sebelumnya pembuktiannya adalah sebagai berikut: (3) H3 diterima, berarti terdapat pengaruh yang signifikan subjective norm dan perceived behavioral control terhadap intention to commit digital piracy.

\section{PENUTUP}

Hasil analisis dengan menggunakan regresi linear berganda menunjukkan bahwa dari kedua variabel independen, yaitu subjective norm $\left(\mathrm{X}_{1}\right)$, perceived behavioral control $\left(\mathrm{X}_{2}\right)$ terhadap intention to commit digital piracy restoran (Y) menunjukkan bahwa terdapat pengaruh yang signifikan. Hal ini sejalan dengan penelitian yang dilakukan oleh Yoon. (2011) yang pada penelitiannya di sebuah universitas di China. Sedangkan dari pengujian hipotesis secara bersama-sama dapat ditarik kesimpulan, terdapat pengaruh yang signifikan subjective norm dan perceived behavioral control terhadap intention to commit digital piracy, dengan persamaan regresi sebagai berikut : $\mathrm{Y}=6,508+0,800\left(\mathrm{X}_{1}\right)-0,517$ $\left(\mathrm{X}_{2}\right)$.

Saran. Untuk mendapatkan hasil penelitian yang lebih akurat, disarankan menambah jumlah sampel dalam penelitian serupa agar hasil penelitian dapat lebih akurat, dan juga 
dapat menambahkan variabel independen lainnya yang bisa mempengaruhi intention khususnya dalam bidang pembajakan digital.

\section{DAFTAR RUJUKAN}

Aritonang, Lerbin R. (2007) Riset Pemasaran. Teori dan Praktik. Bogor: Ghalia Indonesia Imam Ghozali. (2006) Aplikasi Analisis Multivariate dengan program SPSS. Cetakan IV. Semarang: Badan Penerbit Universitas Diponegoro.

J. Supranto M.A. APU, Prof. (2003) Metode riset aplikasi dalam pemasaran. Cetakan kedua. Edisi tujuh. Jakarta : PT Rineka Cipta.

Mudrajad Kuncoro. (2003) Metode Riset untuk Bisnis dan Ekonomi. Jakarta: Erlangga. Sugiyono. (2006) Statistik Untuk Penelitian. Cetakan Kesembilan. Bandung: Alfabeta.

Yoon, Cheolho (2011) "Theory of planned behavior and ethics theory in digital piracy: an integrated model", Journal of Business Ethics. 100: 405-417. 